\title{
Mechanical Property and Joining Characteristics of Laser Direct Joining of CFRP to Polyethylene Terephthalate
}

\author{
Kwang-Woon Jung',", Yousuke Kawahito', and Seiji Katayama' \\ 1 Joining and Welding Research Institute, Osaka University,11-1 Mihogaoka, Ibaraki, Osaka 567-0047, Japan \\ \# Corresponding Author / E-mail: jkwpc@jwri.osaka-u.ac.jp, TEL: +81-6-6879-8695, FAX: +81-6-6879-8689
}

KEYWORDS : Laser direct joining, Diode laser, CFRP, Polyethylene Terephthalate, Plastic elongation

\begin{abstract}
This study was performed to investigate the joining possibility and characteristics of the dissimilar joint between carbon fiber reinforced plastics (CFRP) and amorphous polyethylene terephthalate (PET) plastic using a continuous wave (cw) diode laser with a line-shaped beam. Tensile shear test results demonstrated that strong lap joints with a maximum load of $3200 \mathrm{~N}$ could be produced under some proper conditions, and base amorphous PET plastic sheet was elongated without fracture. It was confirmed from SEM observation that the dissimilar lap joint was tightly bonded near the joint interface between two materials, and simultaneously integrated by the interdiffusion and mixing process at the joint interface of two materials through rapid melting, solidification and cooling during laser joining. Through high speed video camera observation, the joining phenomena generating in the laser irradiated part during laser joining of CFRP to PET was obviously identified. Consequently, it was revealed that strong dissimilar lap joint of CFRP to engineering plastic could be possible by a direct laser irradiation without adhesive bonds or mechanical fasteners.
\end{abstract}

\section{NOMENCLATURE}

$\theta=$ Incident angle of laser head

$P=$ Laser power

$v=$ Travelling speed of stage

\section{Introduction}

In recent years, a demand for CFRP composite material with light weight, high strength and no corrosion in comparison with commercially available engineering metals is rapidly increasing in the industrial applications such as aerospace, automotives, sports and constructions. $^{1-6}$ A product in an industry is usually desirable to complete final goods by only the integral molding. But, a final product of CFRP material with complicated shapes such as a round shape and a curved surface is well known to be difficult to manufacture with only a molding process. Therefore, in order to use effectively CFRP material without the limitations of configuration or location, the development of various manufacturing technologies such as cutting, drilling and joining is needed. ${ }^{7-13}$ Among others, a direct joining of CFRP to metal or plastic is important and necessary for their widespread applications and an improvement in the production performance concerning light weight, flexibility, downsizing and multi-functionality.

Conventional joining technologies of CFRP to metal or plastic have been usually performed by using adhesive bonds, mechanical fasteners like bolts or rivets, and hybrid bonded-bolted lap joints. ${ }^{14-17}$ However, it was well known that these joining methods led to several problems such as environmental pollution accompanying volatile organic compounds emission, long processing time, non-uniform joint strength in the case of adhesive bonding, and the limitations of degree freedom caused by hole drilling, low productivity and fracture due to concentrated load transmissions in the case of mechanical fasteners. In order to solve the above mentioned problems, the advanced technologies such as resistance welding, ${ }^{18}$ laser assisted metal and plastic joining (named LAMP joining in brief), ${ }^{19}$ ultrasonic metal welding $^{20}$ and friction spot welding ${ }^{21}$ for a joining of CFRP-plastic or metal and metal-plastic have been actively researched.

Through the LAMP joining process, the authors succeeded laser 
direct joining of CFRP to different metals such as stainless steel, zinc coated steel and aluminum alloy using a high power and high brightness cw disk laser with a near Gaussian beam and a high quality $\mathrm{cw}$ diode laser with a line-shaped beam. ${ }^{22-24}$ These researches demonstrated that strong lap joints of more than $3000 \mathrm{~N}$ could be produced by chemical or physical bonding on atomic or molecular sized level generating between the melted plastic and a nanometer thick oxide film existing on the metal surface near the joint interface, as well as mechanical bonding (Anchor effect) that the melted plastic was generated to closely flow in grooves or holes existing on the metal surface. On the other hand, lots of researches for a joining of CFRP to metals have been reported by this time, but there are a few trials to directly join CFRP and engineering plastic using a laser heat source, $^{25,26}$ and the joining characteristics generating at the joint interface of two materials were not fully understood.

In this research, therefore, laser direct joining of polyacrylonitrile (PAN) type CFRP plate to amorphous PET plastic sheet was performed to investigate the joining possibility and characteristics for the dissimilar lap joint using a cw diode laser with a line-shaped beam. Tensile shear loads (or strengths) for laser direct lap joints of CFRP to amorphous PET were evaluated by the tensile test. The melted zone of the laser irradiated part and macro- or micro-structure near the joint interface were observed by optical microscope (OM) and scanning electron microscope (SEM) in detail. Furthermore, joining phenomena generating at the joint interface during laser joining of CFRP to amorphous PET was examined by high speed video camera observation.

\section{Materials and Experimental Procedures}

The materials used in laser direct joining experiments are PAN type CFRP plate and commonly available amorphous PET plastic sheet purchased. PAN type CFRP used was consisted of the matrix plastic of polyamide 6 (PA6) with the volume of $80 \%$ and fiber orientation of the long fiber pellet of chopped carbon fibers with the volume of $20 \%$ and manufactured by injection molding. The dimensions of CFRP plate used in laser joining experiments were the thickness of $3 \mathrm{~mm}$, the width of $20 \mathrm{~mm}$ and the length of $100 \mathrm{~mm}$. Here, the average tensile shear load (or strength) of four base CFRP specimens was about $9000 \mathrm{~N}$ (or $150 \mathrm{MPa}$ ) in the tensile test with the gauge length of $40 \mathrm{~mm}$ at the travelling speed of $0.33 \mathrm{~mm} / \mathrm{s}$.

The dimensions of amorphous PET sheet used were the thickness of $2 \mathrm{~mm}$, the width of $30 \mathrm{~mm}$ and the length of $70 \mathrm{~mm}$. The average tensile shear load of four amorphous PET specimens was about $3200 \mathrm{~N}$ in the tensile test. The pyrolysis temperatures (Åé) for PA6 and amorphous PET plastic used were about 180 and 210, respectively.

Fig. 1 indicates a schematic experimental setup for laser direct joining of PAN type CFRP plate to amorphous PET sheet. CFRP and amorphous PET in this research played a role of the absorbent and the transparent material, respectively. As shown in Fig. 1, amorphous PET sheet was directly overlapped on CFRP plate, and two materials were tightly fixed by pressing two bridge plates by four bolts. About $60 \mathrm{~N} \bullet \mathrm{cm}$ torque was equally applied to each bolt. No gap tolerance exists between two materials. The maximum laser power, the wavelength and the focal distance of the $\mathrm{cw}$ diode laser used in these experiments were $3 \mathrm{~kW}, 800 / 940 \mathrm{~nm}$ and $100 \mathrm{~mm}$, respectively. The diode laser beam used was a line-shaped beam of $0.6 \times 11 \mathrm{~mm}$ at the focal point. The incident angle (q) of the laser head used was 5 to avoid the reflected light toward laser focusing lens. The diode laser beam was directly irradiated on $3 \mathrm{~mm}$ thick CFRP plate after transmitted amorphous PET plastic sheet. Laser joining conditions used were the laser powers from $60 \mathrm{~W}$ to $200 \mathrm{~W}$, the travelling speed of $15 \mathrm{~mm} / \mathrm{s}$ and the focus position of $0 \mathrm{~mm}$. $\mathrm{N}_{2}$ shielding gas was used at $30 \mathrm{~L} / \mathrm{min}$ flow to cool the PET sheet surface and to suppress surface contamination. Table 1 shows the maximum temperature data measured at the melted zone under various laser powers. In order to evaluate joining possibility and strengths for CFRP-PET lap joints made at various joining conditions, the tensile shear test was conducted under the conditions of the travelling speed of $0.33 \mathrm{~mm} / \mathrm{s}$ and the gauge length of about $80 \mathrm{~mm}$. The melted zone of the laser irradiated part and the macro- or micro-structure near the joint interface were observed by OM and SEM in detail. Furthermore, in order to visually observe joining phenomena during laser direct joining of CFRP to amorphous PET, high speed video camera was employed. A laser irradiated part was observed at 500 frames/s by using the spectral filter with the wavelength between $400 \mathrm{~nm}$ and $800 \mathrm{~nm}$ under the illumination of commonly available LED lamp.

\section{Results and Discussion}

\subsection{Strong Laser Lap Joint Between CFRP and PET}

Laser direct joining of CFRP to PET was performed by directly irradiating the cw diode laser with the line-shaped beam on the top surface of CFRP plate after transmitted amorphous PET sheet.

Fig. 2 represents the appearances on the top and bottom surface for the lap joints produced by laser joining of CFRP plate to PET sheet.

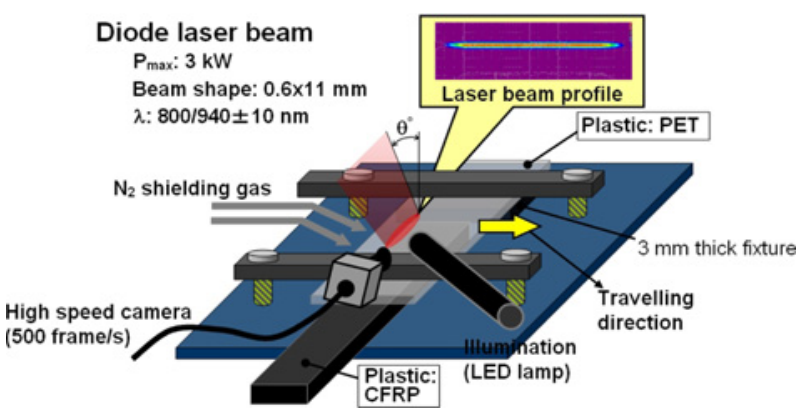

Fig. 1 Schematic experimental setup of laser direct joining of CFRP to PET, and laser joining process by cw diode laser beam

Table 1 Comparison of temperature data measured at melted zone

\begin{tabular}{cc}
\hline Laser power $(\mathrm{W})$ & Maximum Temperature $\left({ }^{\circ} \mathrm{C}\right)$ \\
\hline 60 & 203 \\
\hline 80 & 215 \\
\hline 100 & 257 \\
\hline 110 & 314 \\
\hline 125 & 451 \\
\hline 150 & 524 \\
\hline 200 & 580 \\
\hline
\end{tabular}


The laser power and the travelling speed used were $100 \mathrm{~W}$ and $15 \mathrm{~mm} /$ $\mathrm{s}$, respectively. It is seen that the dissimilar lap joints between CFRP and amorphous PET could be possible by only a laser irradiation without surface treatment or adhesive bonds. And, it is observed in Fig. 2(a) that the melted zone with slightly wider area than the size of the line-shaped beam was generated at the joint interface of CFRP and amorphous PET, and some melted plastic at the start or end points of the laser irradiated part flowed out. These results are attributed to the effect of higher thermal conduction caused by carbon fibers in CFRP plate and an activated flow due to strong dynamic movement between PA matrix plastic in CFRP plate and amorphous PET sheet melted during laser irradiation.

In order to evaluate the joint strengths for laser direct lap joints of CFRP to amorphous PET, the tensile shear test was conducted. Fig. 3 indicates tensile shear test results of laser lap joints of CFRP plates to amorphous PET sheets made at different laser powers from $60 \mathrm{~W}$ to $200 \mathrm{~W}$. The results show that the average value of tensile shear load of the joints obtained at the laser power of $60 \mathrm{~W}$ was about $2700 \mathrm{~N}$ less than that of base amorphous PET, and the joints was fractured on the base amorphous PET. The joints made at the laser powers from $80 \mathrm{~W}$ to $125 \mathrm{~W}$ had the maximum load of $3200 \mathrm{~N}$ similar to that of base amorphous PET, and especially all lap joints made at the laser powers of $100 \mathrm{~W}$ and $110 \mathrm{~W}$ were elongated without fracture. In addition, it was founded that the laser lap joint of CFRP to PET could be produced at the range of the laser heat input (about 4 to $13 \mathrm{~J} / \mathrm{mm}$ ), which was by far smaller than that (about 50 to $600 \mathrm{~J} / \mathrm{mm}$ ) of CFRP-metals

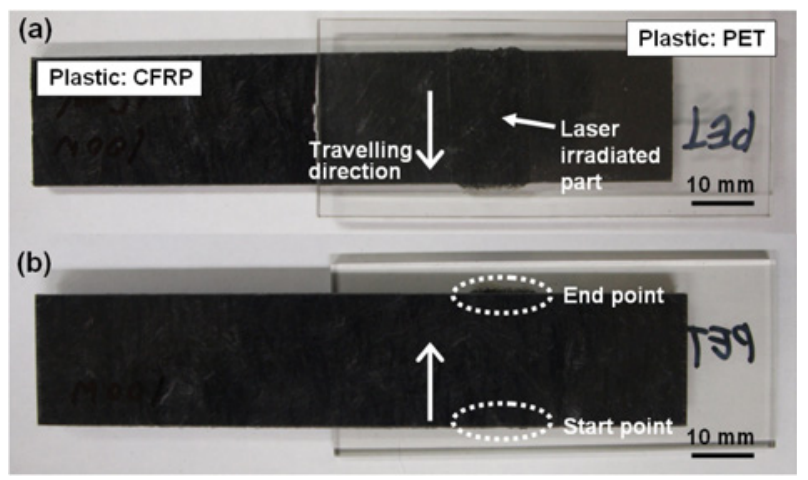

Fig. 2 Laser lap joints of CFRP to PET made, showing surface appearances of top surface (a) and bottom surface (b) of joint

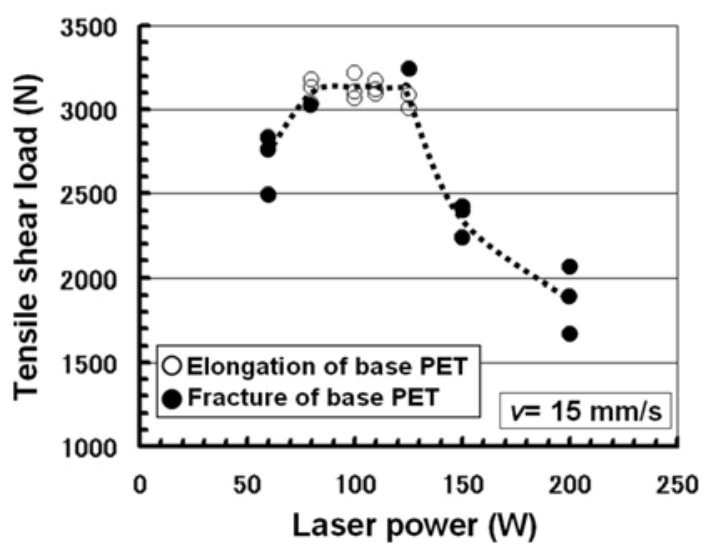

Fig. 3 Tensile shear test results of laser direct lap joints produced under various joining conditions combinations reported by the authors. ${ }^{22-24}$ Here, the laser heat input $(P /$ v) means in inverse proportion to the travelling speed. However, more than the laser power of $125 \mathrm{~W}$, the tensile shear loads of the joints seemed to decrease with increasing the laser power. The average tensile shear loads of the joints made at the laser powers of $150 \mathrm{~W}$ and $200 \mathrm{~W}$ were about $2300 \mathrm{~N}$ and $1900 \mathrm{~N}$, respectively. And, all lap joints were fractured on base amorphous PET. It was regarded that strength reduction of the joints made at high laser powers was due to the increase in thermal degradation of base PA plastic in CFRP and base amorphous PET near the joint interface caused by the excessive temperature rise, as shown in Table 1 .

The appearances of the lap joints after tensile shear tests were observed in detail, as shown in Fig. 4. At the laser power of $60 \mathrm{~W}$, it is seen that the progress of the detachment at both corners of the jointed part became to start and moved into the jointed part, and then the main fracture occurred firstly at the middle point of the jointed part, in which two detachments dashed against each other. It is attributed to the effect of stress concentration at that point. At the laser powers from $80 \mathrm{~W}$ to $125 \mathrm{~W}$, base amorphous PET sheet of the joints were elongated at the edge of the jointed part without fracture. On the other hand, at the laser powers of $150 \mathrm{~W}$ and $200 \mathrm{~W}$, it is observed that the joints were fractured at the both edges of the jointed part, and some oils from the start or end points of the laser irradiated part flowed out. It was regarded that these results were due to the effects of thermal stress concentration generated at the edges of the jointed part during laser joining and thermal degradation caused by excessive melting of PA matrix plastic in CFRP and base amorphous PET.

Consequently, it was confirmed that the dissimilar lap joint of CFRP to amorphous PET was possible by only a laser irradiation, and the joint made by the adequate laser heat input was elongated without any fracture.

\subsection{Microstructure Characteristics of Joint Interface and Joining Phenomena during Laser Joining of CFRP to PET}

The laser lap joint between CFRP and amorphous PET were examined in detail. The jointed parts for the laser lap joints of CFRP to amorphous PET were observed by OM, as shown in Fig. 5. The laser powers used were $100 \mathrm{~W}$ and $200 \mathrm{~W}$, respectively. The results show

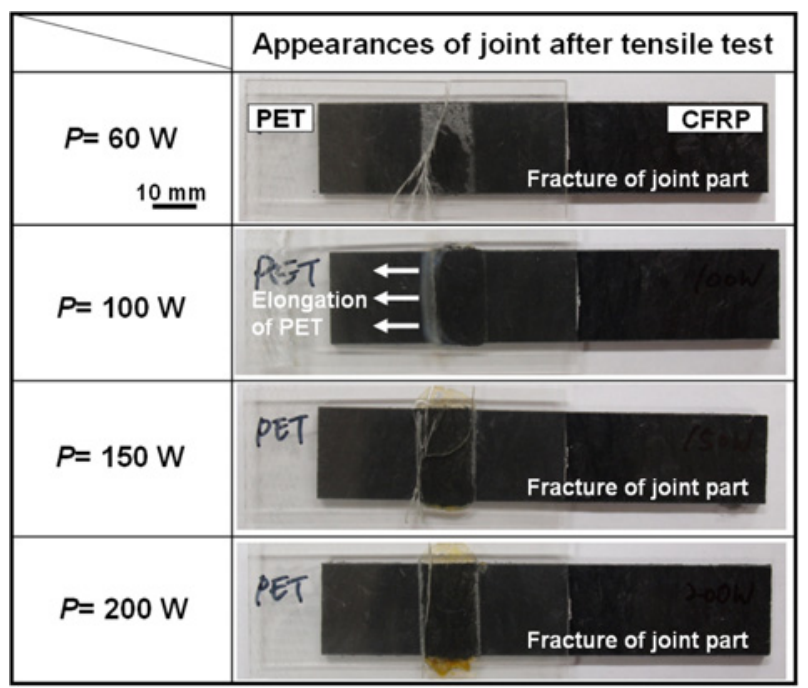

Fig. 4 Appearances of CFRP-PET lap joints fractured after tensile test 
that many bubbles with micrometer size on the jointed part of both joints were generated irregularly at the whole area of the melted zone, and especially the bubbles were mainly formed on carbon fibers in CFRP. It was because of the physical properties, such as high thermal conduction and high laser absorption, of carbon fibers existing in CFRP during laser irradiation. ${ }^{22}$ And, it is observed that some carbon fibers at the end point of the laser irradiated part flowed out at the laser power of $200 \mathrm{~W}$, and simultaneously small bubbles existed widely in the melted zone.

Microstructure characteristics at the joint interface of CFRP to amorphous PET were investigated. Fig. 6 represents cross-sectional SEM photos near the interface of the laser lap joint between CFRP and amorphous PET. The laser power and the travelling speed used were $100 \mathrm{~W}$ and $15 \mathrm{~mm} / \mathrm{s}$, respectively. The results show that the joint of CFRP to amorphous PET made by only a laser irradiation was tightly bonded without gap or thermal damage near the joint interface, and base PA matrix plastic in CFRP and base amorphous PET were completely mixed through rapid melting, solidification and cooling process during laser joining. It was revealed that the interdiffusion process at the joint interface of two materials by melting and mechanical bonding by the confusion between carbon fibers and the melted PET plastic near the joint interface could be obtained. ${ }^{27,28}$

In order to further investigate the joining phenomena generating during laser joining of CFRP to PET, high speed video camera observation for the laser irradiated part was performed.

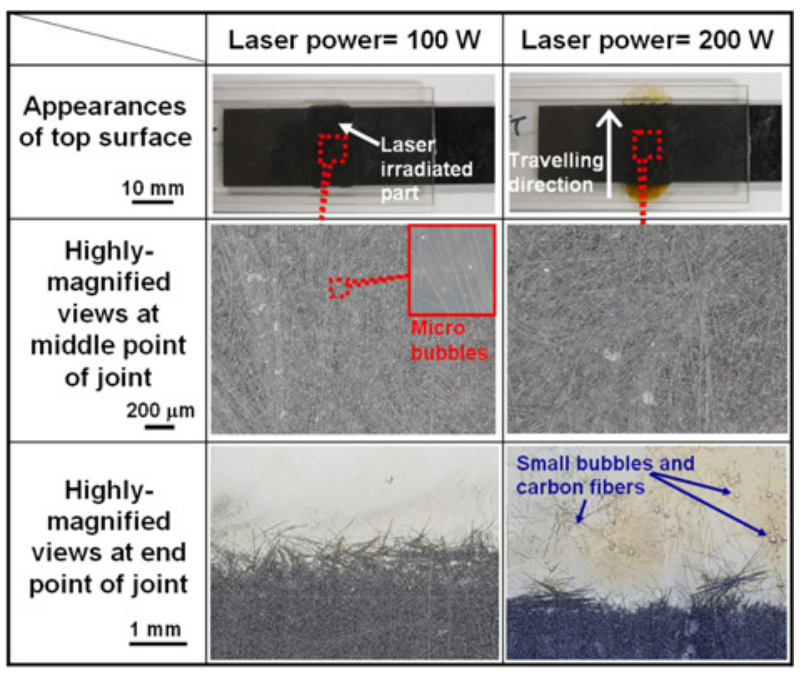

Fig. 5 Images of jointed part of CFRP-PET lap joints produced at laser powers of $100 \mathrm{~W}$ and $200 \mathrm{~W}$

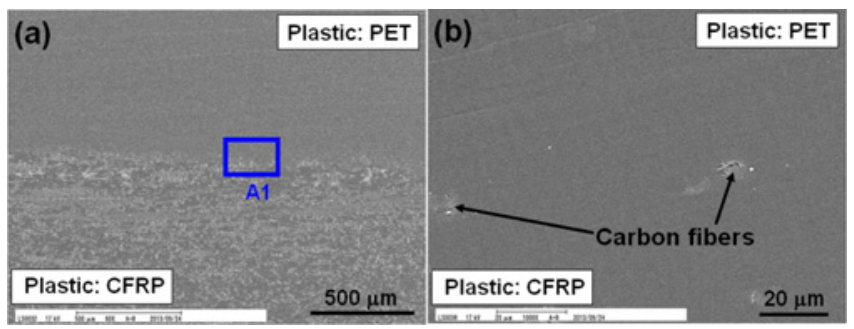

Fig. 6 Cross-sectional SEM photos of joint interface of CFRP to PET: (a) lower magnification and (b) higher magnification corresponding to boxed region of $\mathrm{A} 1$
Fig. 7 indicates high speed video observation results for the laser irradiated part during laser joining of CFRP to PET. The laser power used was $100 \mathrm{~W}$. It is observed that CFRP material at the moment irradiated directly on the surface of CFRP after the laser beam transmitted PET started to heat and melt through the laser absorption. Then, at the time of $0.1 \mathrm{~s}$, small bubbles with the air and white pyrolysis gas near the front of the laser beam irradiation zone were formed. Through the generation of the pyrolysis gas, it was confirmed that thermal reaction caused by the temperature rise more than the pyrolysis temperature of base amorphous PET during laser joining could be accomplished, as shown in Table 1. At the time of $0.28 \mathrm{~s}$, the bubbles generated at the front of the laser beam became to expand and moved towards the outside of the laser beam. It is observed that the dynamic movement of the melted plastic in the melted zone between two materials was generated. Also, the melted plastic flowed out backwards the laser beam and came to go through rapid solidification process. At the time from $0.6 \mathrm{~s}$ to $1.25 \mathrm{~s}$, the bubbles at the front of the laser beam seemed to be expanded more largely. It was because of high pressure rise generated by rapid expansion of the bubbles caused by continuous heat accumulation in the material during laser joining. After the time of $1.32 \mathrm{~s}$, some carbon fibers and white pyrolysis gas at the end of the joint were observed to flow out, and big bubbles in the front of the laser beam disappeared.

From the above-obtained results, the laser joining process of CFRP to amorphous PET could be interpreted, and the representation of joining mechanism is schematically shown in Fig. 8. It was confirmed
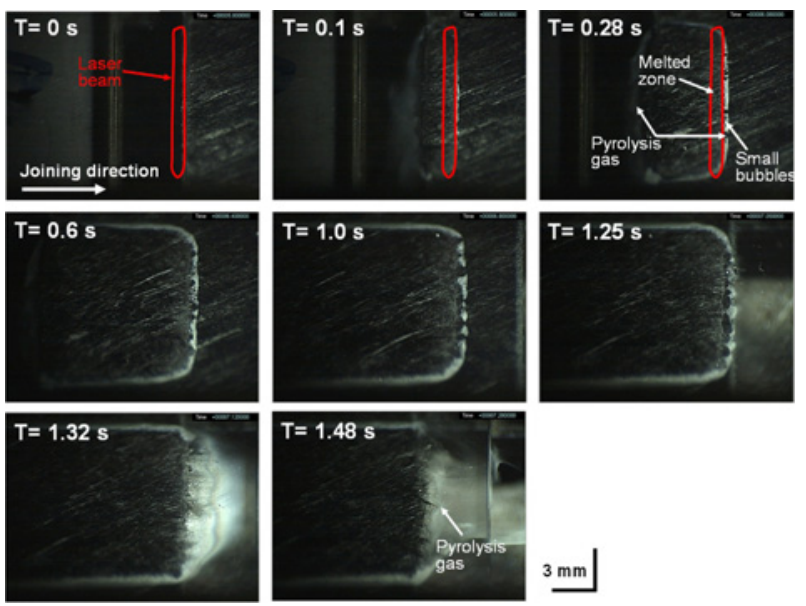

Fig. 7 High speed video observation results of laser irradiated part during laser joining of CFRP to amorphous PET

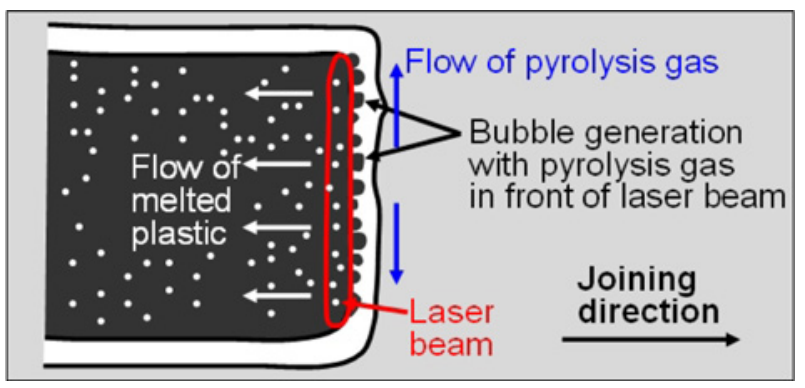

Fig. 8 Joining mechanism of laser direct joining process between PAN type CFRP plate and amorphous PET sheet 
that some bubbles with the air and pyrolysis gas in the front of the diode laser beam irradiation zone during laser joining were generated and flowed out forward the laser beam, and simultaneously small bubbles with micrometer size were mainly formed on carbon fibers in CFRP, as well as the melted plastic of both materials near the joint interface appeared the dynamic movement. In addition, it was revealed that the strong lap joint accompanying the elongation of base amorphous PET could be produced through laser joining process, and the joint was integrated by the interdiffusion and mixing process between two materials through rapid melting, solidification and cooling during laser joining.

\section{Conclusions}

Laser direct joining experiments of CFRP to amorphous PET were performed by irradiating the $\mathrm{cw}$ diode laser with the line-shaped beam directly on the amorphous PET sheet overlapped on the CFRP plate. It was confirmed that the strong lap joint with tensile shear load of about maximum $3200 \mathrm{~N}$ could be produced under some proper conditions, and base amorphous PET part of the joint was elongated without fracture. Through SEM observation of the joint interface, it was revealed that the joint was tightly bonded without gap or big thermal damage between two materials, and completely mixed by the interdiffussion process of two melted plastic materials according to rapid melting, solidification and cooling in the laser irradiated part during laser joining. Furthermore, high speed video observation results demonstrated that small bubbles with the air and white pyrolysis gas in the front of the laser beam during laser joining started to be generated, and simultaneously the bubbles of micrometer size in the melted zone of the laser beam were mainly formed on carbon fibers. Then, the melted plastic flowing backwards the laser beam solidified rapidly. It was consequently judged that laser direct joining process of CFRP to engineering plastic would largely contribute to the development of industrial technology because adhesive bonds and mechanical fasteners such as bolts and rivets are not needed.

\section{REFERENCES}

1. Roberts, T., "Rapid Growth Forecast for Carbon Fibre Market," Reinforced Plastics, Vol. 51, No. 2, pp. 10-13, 2007.

2. Beardmore, P. and Johnson, C. F., "The Potential for Composites in Structural Automotive Applications," Composites Science and Technology, Vol. 26, No. 4, pp. 251-281, 1986.

3. Williams, J. C. and Starke Jr, E. A., "Progress in Structural Materials for Aerospace Systems,” Acta Materialia, Vol. 51, No. 19, pp. 57755799, 2003.

4. Mohammed, B. S., Ean, L.W., and Malek, M. A., "One Way RC Wall Panels with Openings Strengthened with CFRP," Constr. Build. Mater., Vol. 40, pp. 575-583, 2013.

5. Soutis, C., "Carbon Fiber Reinforced Plastics in Aircraft Construction," Materials Science and Engineering: A, Vol. 412, No.
1-2, pp. 171-176, 2005.

6. Ahn, S., Hong, S., Koo, J., and Seok, C., "Prediction of Compressive Strength of CFRP Composite Structures using Notch Strength,” Int. J. Precis. Eng. Manuf., Vol. 14, No. 6, pp. 1103-1108, 2013.

7. Cenna, A. A. and Mathew, P., "Analysis and Prediction of Laser Cutting Parameters of Fibre Reinforced Plastics (FRP) Composite Materials,” Int. J. Mach. Tool. Manuf., Vol. 42, No. 1, pp. 105-113, 2002.

8. Jung, K. W., Kawahito, Y., and Katayama, S., "Ultra-high Speed Disk Laser Cutting of Carbon Fiber Reinforced Plastics," J. Laser. Appl., Vol. 24, No. 1, Paper No. 012007-1-8, 2012.

9. Bhatnagar, N., Ramakrishnan, N., Naik, N. K., and Komanduri, R., "On the Machining of Fiber Reinforced Plastic (FRP) Composite Laminates,” Int. J. Mach. Tools Manuf., Vol. 35, No. 5, pp. 701-716, 1995.

10. Xu, J., An, Q., Cai, X., and Chen, M., "Drilling Machinability Evaluation on New Developed High-Strength T800S/250F CFRP Laminates," Int. J. Precis. Eng. Manuf., Vol. 14, No. 10, pp. 16871696, 2013.

11. Shahrajabian, H. and Farahnakian, M., "Modeling and MultiConstrained Optimization in Drilling Process of Carbon Fiber Reinforced Epoxy Composite,” Int. J. Precis. Eng. Manuf., Vol. 14, No. 10, pp. 1829-1837, 2013.

12. Park, K. H., Beal, A., Kim, D., Kwon, P., and Lantrip, J., “Tool Wear in Drilling of Composite/Titanium Stacks using Carbide and Polycrystalline Diamond Tools," Wear, Vol. 271, No. 11-12, pp. 2826-2835, 2011.

13. Shanmugam, D. K., Nguyen, T., and Wang, J., "A Study of Delamination on Graphite/Epoxy Composites in Abrasive Waterjet Machining," Composites Part A: Applied Science and Manufacturing, Vol. 39, No. 6, pp. 923-929, 2008.

14. Rhee, K. Y., Choi, N.-S., and Park, S.-J., "Surface Treatment of CFRP Composites by Ar+ Irradiation to Improve Bonding Strength between Aluminum and CFRP Composites," Polym. Compos., Vol. 23, No. 6, pp. 1151-1161, 2002.

15. Kelly, G., "Load Transfer in Hybrid (bonded/bolted) Composite Single-Lap Joints," Compos. Struct., Vol. 69, No. 1, pp. 35-43, 2005.

16. Kumar, S. B., Sridhar, I., Sivashanker, S., Osiyemi, S. O., and Bag, A., "Tensile Failure of Adhesively Bonded CFRP Composite Scarf Joints,” Mater. Sci. Eng. B, Vol. 132, No. 1-2, pp. 113-120, 2006.

17. Kolesnikov, B., Herbeck, L., and Fink, A., "CFRP/titanium Hybrid Material for Improving Composite Bolted Joints," Compos. Struct., Vol. 83, No. 4, pp. 368-380, 2008.

18. Ageorges, C., Ye, L., and Hou, M., "Experimental Investigation of the Resistance Welding for Thermoplastic-Matrix Composites. Part I: Heating Element and Heat Transfer," Compos. Sci. Technol., Vol. 60, No. 7, pp. 1027-1039, 2000. 
19. Katayama, S. and Kawahito, Y., "Laser Direct Joining of Metal and Plastic,” Scr. Mater., Vol. 59, No. 12, pp. 1247-1250, 2008.

20. Balle, F., Wagner, G., and Eifler, D., "Ultrasonic Metal Welding of Aluminium Sheets to Carbon Fibre Reinforced Thermoplastic Composites,” Adv. Eng. Mater., Vol. 11, No. 1-2, pp. 35-39, 2009.

21. Amancio-Filho, S. T., Bueno, C., dos Santos, J. F., Huber, N., and Hage Jr, E., "On the Feasibility of Friction Spot Joining in Magnesium/Fiber-Reinforced Polymer Composite Hybrid Structures," Mater. Sci. Eng. A., Vol. 528, No. 10-11, pp. 38413848, 2011.

22. Jung, K. W., Kawahito, Y., and Katayama, S., "Laser Direct Joining of Carbon Fibre Reinforced Plastic to Stainless Steel," Sci. Technol. Weld. Join., Vol. 16, No. 8, pp. 676-680, 2011.

23. Jung, K. W., Kawahito, Y., Takahashi, M., and Katayama, S., "Laser Direct Joining of Carbon Fiber Reinforced Plastic to Zinc-Coated Steel," Materials \& Design, Vol. 47, pp. 179-188, 2013.

24. Jung, K. W., Kawahito, Y., and Katayama, S., "Laser Direct Joining of Carbon Fiber Reinforced Plastic To Aluminum Alloy,” J. Laser. Appl., Vol. 25, No. 3, Paper No. 032003-1-6, 2013.

25. Jaeschke, P., Herzog, D., Haferkamp, H., Peters, C., and Herrmann, A. S., "Laser Transmission Welding of High-performance Polymers and Reinforced Composites-a Fundamental Study," J. Rein. Plast. Comp., Vol. 29, No. 20, pp. 3083-3094, 2010.

26. Amend, P., Frick, T., and Schmidt, M., "Experimental Studies on Laser-based Hot-Melt Bonding of Thermosetting Composites and Thermoplastics," Physics procedia, Vol. 12, pp. 166-173, 2011.

27. Ageorges, C., Ye, L., and Mou, M., "Advances in Fusion Bonding Techniques for Joining Thermoplastic Matrix Composites: a Review," Composites Part A, Vol. 32, No. 6, pp. 839-857, 2001.

28. Yousefpour, A., Hojjati, M., and Immarigeon, J. P., "Fusion Bonding/Welding of Thermoplastic Composites," J. Thermoplast. Compos., Vol. 17, No. 4, pp. 303-341, 2004. 